\title{
Study of Direct Torque Control Scheme for Induction Motor Based on Torque Angle Closed-Loop Control
}

\author{
Xuande $\mathrm{Ji}^{*}$, Daqing He and Yunwang Ge
}

College of Electrical Engineering and Automation Luoyang Institute of Science and Technology, No.8 XueZi Street Luolong District Luoyang HeNan, 471023, China

\begin{abstract}
For disadvantages of the large flux and torque ripple and current waveform distortion of Direct Torque Control (BASIC-DTC), the DTC scheme for induction motor based on torque angle closed-loop control was presented and the proposed scheme was realized with three methods of torque angle closed-loop control. The main characteristics of three methods of torque angle closed-loop control for the proposed scheme was analyzed, emphasizing their advantages and disadvantages. The performance of three methods of torque angle closed-loop control for the proposed scheme was studied in terms of flux and torque ripple, current waveform distortion and transient responses. Simulation results showed that the proposed scheme improves the performance of induction motor BASIC-DTC by combining low flux ripple, low torque ripple and low current waveform distortion's characteristics with fast dynamics.
\end{abstract}

Keywords: BASIC-DTC, Closed-Loop, Induction Motor, SVM, Torque Angle Control.

\section{INTRODUCTION}

The adjustable speed drives (ASD) is generally used in elevators, electric vehicles, hybrid electric vehicles, pumps, robotics, wind power generation and ship propulsion systems etc. DC motor is mainly used in DC-ASD, and induction motor is mainly used for AC-ASD [1].

The natural decoupling between flux and torque is achieved due to DC motor's unique internal structure, thus DC-ASD has a good and fast dynamic response. DC motor has been dominant in industrial applications over the past few decades. However, DC motor has the disadvantages of higher cost, higher rotor inertia and maintenance difficulties with brushes and commutator. In addition, DC motor cannot operate in dirty and explosive environments. Induction motor has not the disadvantages of DC motor. Therefore, DC motor will be gradually substituted with induction motor.

Induction motor's control is much more complex than DC motor because of its mathematical model that has the nature of nonlinear, multivariable and strong couple.

Field Oriented Control [2] (FOC) was proposed by F. Blashke in early 1970. FOC makes induction motor have a similar performance to the DC motor in static and dynamic characteristics. An accurate flux estimator had to be employed to ensure the estimated value used in calculation does not deviate from the actual value. Besides, the coordinate transformation had increased the complexity of this control method.

*Address correspondence to this author at the College of Electrical Engineering and Automation Luoyang Institute of Science and Technology, No.8 XueZi Street Luolong District Luoyang HeNan, 471023, China;

Tel: +86-159-3792-0964; E-mail: litdqx@sohu.com
BASIC-DTC was first introduced by M. Depenbrock in $1986[3,6]$. A new direction had opened up for a highperformance control of induction motor. Shortcomings of FOC's control algorithm complexity and rotor parameters' dependence were largely overcome by BASIC-DTC. However, BASIC-DTC also has its own disadvantages such as difficulty to control torque and flux at low-speed, high flux and torque ripple, high current waveform distortion and variable switching frequency.

A large number of technical papers appear in the literature mainly to improve the performance of Induction Motor. SVM-DTC scheme [4] that combined Space Vector Modulation (SVM) and Direct Torque Control (DTC) was widely used in many schemes. SVM-DTC scheme used the PI controller instead of the hysteresis comparator, used the SVM instead of the voltage vector selection table and used the flux observer instead of the pure integrator to solve the problems such as the difficulty to control torque and flux at low-speed, high flux and torque ripple, high current waveform distortion and variable switching frequency. However, due to the three PI controllers of closed-loop flux, speed closed-loop and torque closed-loop, the controller parameters' design becomes difficult, and the rotate inverse transform makes the system structure complex. Thus SVM-DTC scheme lost the advantage of the simple structure of the BASIC-DTC system.

The DTC scheme for induction motor based on torque angle closed-loop control was presented in this paper. According to the approximate linear relationship between electromagnetic torque and torque angle, the torque angle closed-loop control instead of the closed-loop torque control, the flux tracking control instead of the flux closed-loop control and the flux estimator instead of the pure integrator were used to achieve the control of the flux and torque. Three methods were used for torque angle closed-loop control: 
(1) Torque angle difference closed-loop control; (Method-First).

(2) Torque angle PI controller closed-loop control; (Method-Second).

(3) Torque angle compensation closed-loop control; (Method -Third).

Three methods of torque angle closed-loop control for the new control scheme were simulated by simulation tool. The simulation results were given. Three methods were compared and analyzed, and finally conclusions were drawn.

\section{INDUCTION MOTOR MODEL AND FLUX OB- SERVER}

The following state equations written in a stationary reference frame describe the dynamic behavior of an induction motor [7-10].

$\frac{d}{d t}\left[\begin{array}{l}\vec{\psi}_{s} \\ \vec{\psi}_{r}\end{array}\right]=\left[\begin{array}{ll}A_{11} & A_{12} \\ A_{21} & A_{22}\end{array}\right]\left[\begin{array}{l}\vec{\psi}_{s} \\ \vec{\psi}_{r}\end{array}\right]+\left[\begin{array}{l}I \\ 0\end{array}\right] \vec{u}_{s}$

The output equation is

$\overrightarrow{i_{s}}=C \vec{\psi}$

Where $\quad I=\left[\begin{array}{ll}1 & 0 \\ 0 & 1\end{array}\right], \quad J=\left[\begin{array}{cc}0 & -1 \\ 1 & 0\end{array}\right]$,

$\vec{u}_{s}=\left[\begin{array}{ll}u_{s \alpha} & u_{s \beta}\end{array}\right]^{T}, \vec{i}_{s}=\left[\begin{array}{ll}i_{s \alpha} & i_{s \beta}\end{array}\right]^{T}, \vec{\psi}=\left[\begin{array}{ll}\vec{\psi}_{s} & \vec{\psi}_{r}\end{array}\right]^{T}$,

$\delta=L_{s} L_{r}-L_{m}^{2}$,

$C=(1 / \delta)\left[\begin{array}{cc}L_{r} I & -L_{m} I\end{array}\right], A_{11}=-\left(R_{s} L_{r} / \delta\right) I$,

$A_{21}=\left(R_{r} L_{m} / \delta\right) I, A_{12}=\left(R_{s} L_{m} / \delta\right) I$,

$A_{22}=-\left(R_{r} L_{s} / \delta\right) I+\omega_{r} J$.

The electromagnetic torque equation is:

$T_{e}^{*}=\frac{3}{2} P_{n} \cdot \frac{L_{m}}{\delta} \cdot \vec{\psi}_{s} \otimes \vec{\psi}_{r}$

Where $P_{n}$ is number of pole pairs.

The motor mechanical equation is:

$\frac{d \omega_{r}}{d t}=P_{n} \frac{T_{e}-T_{l}}{J}$

Where $\omega_{r}$ is motor angular speed.

The flux observer state equation and output equation are:

$\frac{d \hat{\bar{\psi}}}{d t}=\hat{A} \hat{\bar{\psi}}+B \vec{u}_{s}+K\left[\vec{i}_{s}-\hat{\bar{i}}\right]$
$\vec{i}_{s}=C \hat{\bar{\psi}}$

Where $A=\left[\begin{array}{ll}A_{11} & A_{12} \\ A_{21} & A_{22}\end{array}\right], B=\left[\begin{array}{l}I \\ 0\end{array}\right], \hat{\bar{\psi}}=\left[\begin{array}{c}\hat{\bar{\psi}}_{s} \\ \hat{\bar{\psi}}_{r}\end{array}\right] . " \wedge "$

is the estimated value of the observer. $K$ is the gain matrix of the observer. The parameter configuration of the observer's gain matrix can be configured according to the method of Ref [5].

\section{PRINCIPLES OF BASIC-DTC}

The BASIC-DTC principle is to use the deviation of torque amplitude and stator flux amplitude respectively to produce the torque switching signal $L_{T}$ and the flux switching signal $L_{\psi}$ through the hysteresis torque comparator and the flux hysteresis comparator. And the appropriate voltage vector was selected with the voltage vector selection table according to the current position of the stator flux vector $\hat{\bar{\psi}}_{s}$ to achieve the control of the torque and flux [4]. Fig. (1) is a block diagram of the induction motor BASIC-DTC.

BASIC-DTC only realized the "qualitative" control of torque and flux due to not only the limited numbers of the voltage vector, but also the nature of the torque bias and flux bias that were only represented by $L_{T}$ and $L_{\psi}$. Thus the ripple of torque and flux was too high. The application of torque and flux hysteresis comparators led to the variable switching frequency of the inverter, and then led to the higher current waveform distortion. While the pure integrator with observing flux made the performance of control system be worsen at low speed $[11,12]$.

\section{DTC SCHEME FOR INDUCTION MOTOR BASED ON TORQUE ANGLE CLOSED-LOOP CONTROL}

DTC scheme for induction motor based on torque angle closed-loop control is that the straight axis component $u_{s \beta}^{*}$ and quadrature axis component $u_{s \alpha}^{*}$ of the Voltage Space Vector $u_{s}^{*}$ in the $\alpha \beta$-coordinate system were calculated with the $u_{s}^{*}$ calculation formula through the increment $\Delta \theta_{s}$ of the phase angle $\theta_{s}$ of the stator flux by closed-loop control torque, the stator flux reference magnitude $\left|\psi_{s}^{*}\right|$ and the stator flux observing magnitude $\left|\psi_{s}\right|$. And then the PWM signals driving the inverter were generated with using the SVM algorithm to achieve the "quantitative" control of the torque and flux, thereby reducing the flux and torque ripple, reducing the current waveform distortion, and so that the switching frequency is constant. The key to generating inverter drive signals is the calculation of $u_{s}^{*}$. 


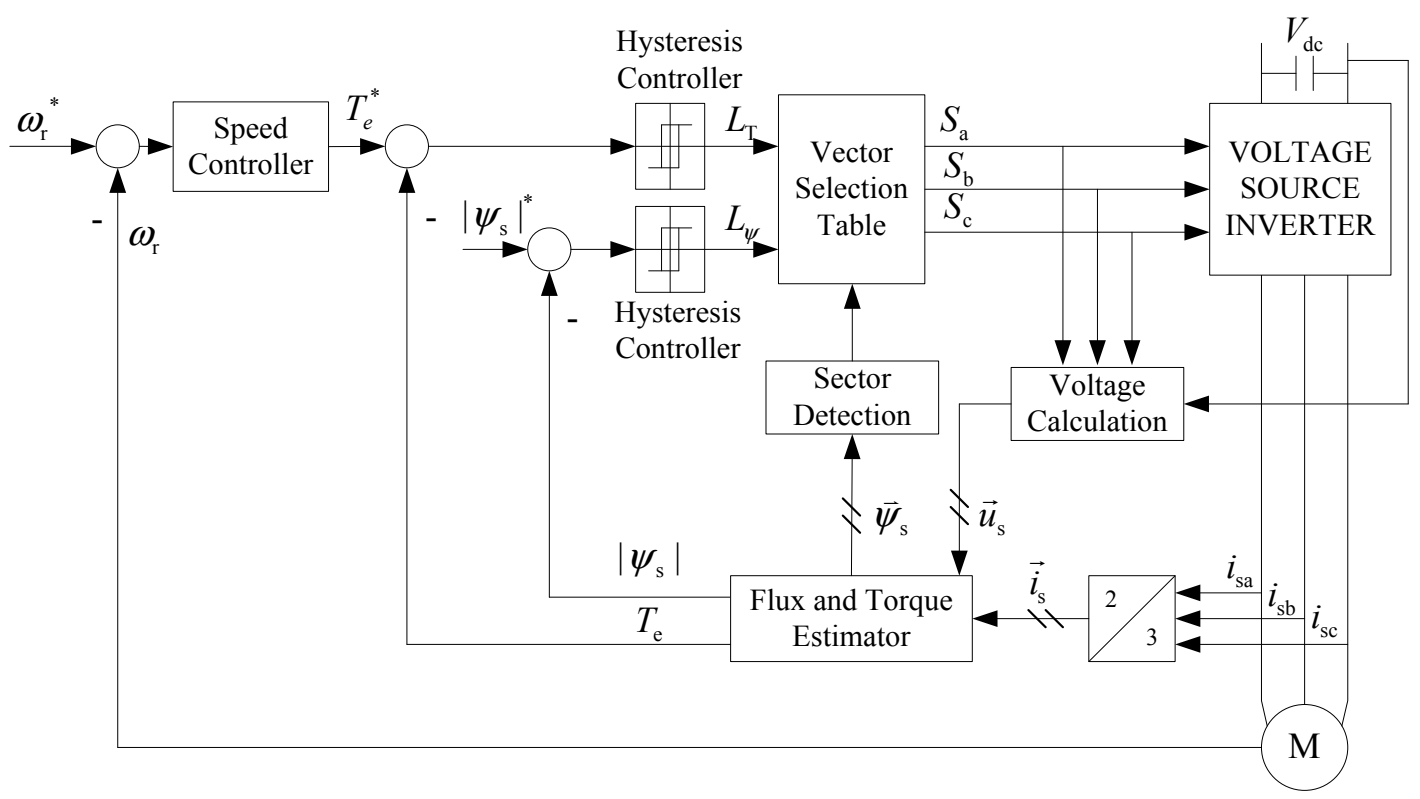

Fig. (1). Block diagram of BASIC-DTC.

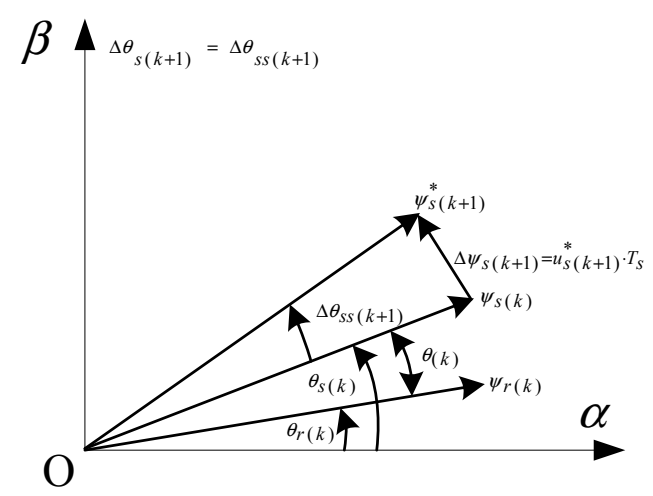

Fig. (2). Stator flux vector in the steady state process.

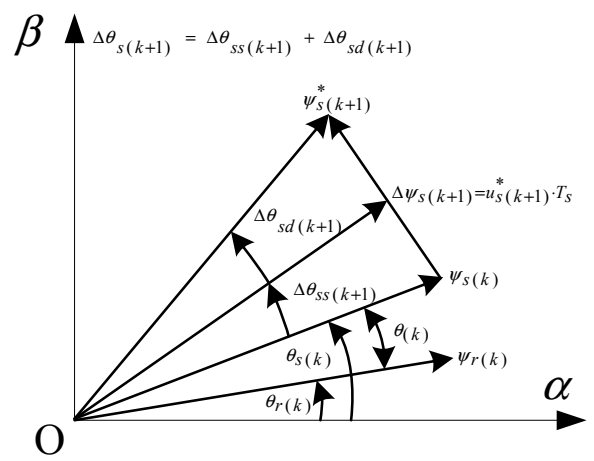

Fig. (3). Stator flux vector in the dynamic process.

Figs. (2 and 3) are respectively the reference stator flux vector $\psi_{s}^{*}$ for calculating $u_{s}^{*}$ in the process of the steadystate and dynamic process [13-15].
In Figs. (2 and 3), $\psi_{r(k)}$ is the $\mathrm{k}$ shot of the rotor flux vector $\psi_{r} \cdot \psi_{s(k)}$ is the $\mathrm{k}$ shot of the stator flux vector $\psi_{s}$. $\psi_{s(k+1)}^{*}$ is the $\mathrm{k}+1$ shot of $\psi_{s}^{*} . \Delta \psi_{s(k+1)}$ is the increment of 


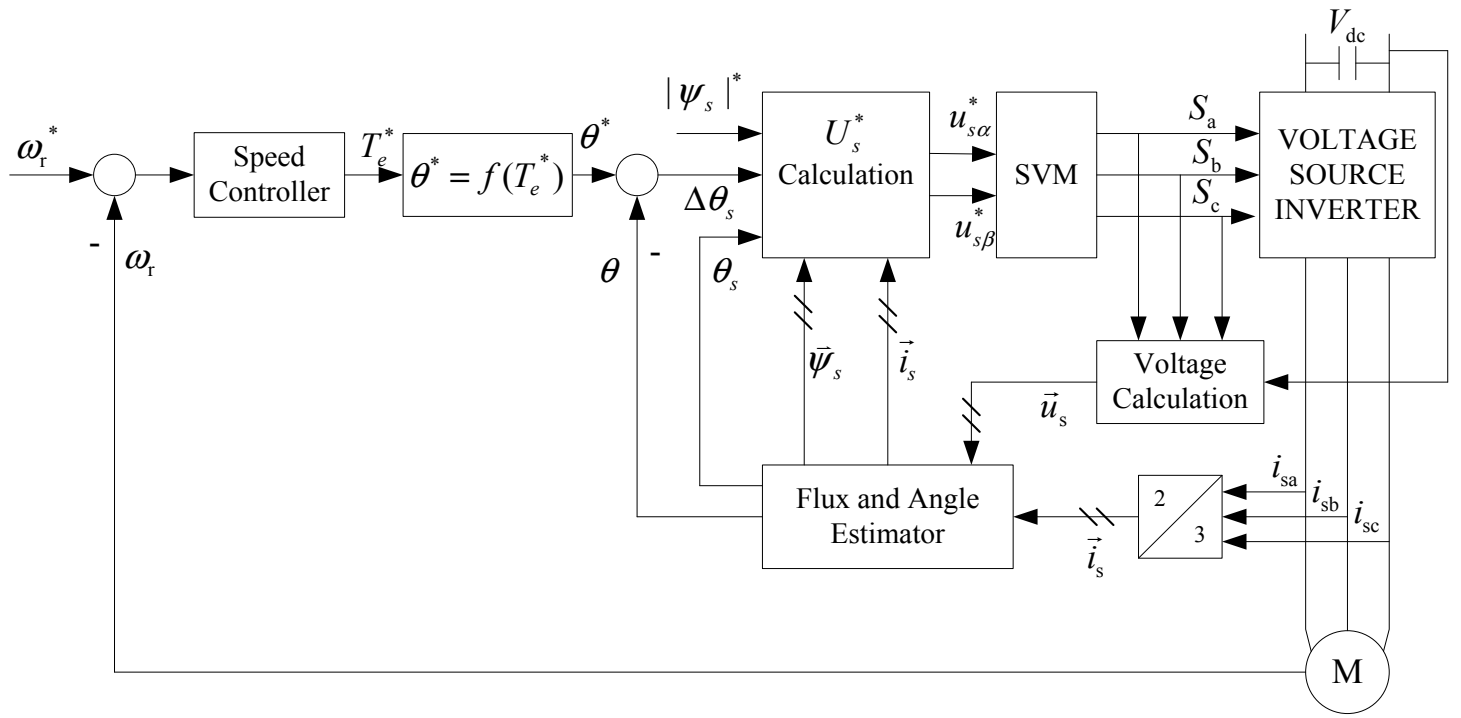

Fig. (4). Block diagram of DTC with closed-loop control of torque angle difference.

$\psi_{s}$ from $\mathrm{k}$ shot to $\mathrm{k}+1$ shot. $\theta_{s(k)}$ is the phase angle of $\psi_{s(k)}$ in the $\alpha \beta$-coordinate system. $\theta_{r(k)}$ is the phase angle of $\psi_{r(k)}$ in the $\alpha \beta$-coordinate system. $\theta_{(k)}$ is the $\mathrm{k}$ shot of torque angle $\theta$, that is the phase difference between $\psi_{s(k)}$ and $\psi_{r(k)}$ that represents the size of the $\mathrm{k}$ shot torque. $\Delta \theta_{s(k+1)}$ is the increment of $\theta_{(k)}$, that is the increment of torque from $\mathrm{k}$ shot to $\mathrm{k}+1$ shot. $\omega_{1}$ is the synchronous speed of induction motor, $T_{s}$ is the control period of the system.

The increment of $\Delta \theta_{s(k+1)}$ consists of two parts: dynamic phase angle increment $\Delta \theta_{s d(k+1)}$ and steady-state phase angle increment $\Delta \theta_{s s(k+1)}$.

When the system is in the steady-state process, due to the balance between the electromagnetic torque and load torque, $\Delta \theta_{s d(k+1)}=0$, and then the increment of $\Delta \theta_{s(k+1)}$ is:

$\Delta \theta_{s(k+1)}=\Delta \theta_{s s(k+1)}=\omega_{1} T_{s}$

As shown in Fig. (2).

When the system is in the dynamic process, due to the imbalance between the electromagnetic torque and load torque, $\Delta \theta_{s d(k+1)} \neq 0$, and then the increment of $\Delta \theta_{s(k+1)}$ is:

$\Delta \theta_{s(k+1)}=\Delta \theta_{s d(k+1)}+\Delta \theta_{s s(k+1)}$

As shown in Fig. (3).

In order to arbitrarily control the electromagnetic torque within a control period $T_{s}$, the phase angle of the stator flux $\psi_{s}$ requires to be increased from $\theta_{s(k)}$ to $\theta_{s(k)}+\Delta \theta_{s(k+1)}$.

Fig. (3) shows: $\psi_{s(k+1)}^{*}=\left|\psi_{s}\right|^{*} e^{j\left(\theta_{s(k)}+\Delta \theta_{s(k+1)}\right)}$

$\psi_{s(k)}=\left|\psi_{s}\right| e^{j \theta_{s(k)}}$

then

$\Delta \psi_{s(k+1)}=\left|\psi_{s}\right|^{*} e^{j\left(\theta_{s(k)}+\Delta \theta_{s(k+1)}\right)}-\left|\psi_{s}\right| e^{j \theta_{s(k)}}$

and so

$u_{s(k+1)}^{*}=\Delta \psi_{s(k+1)} / T_{s}$

Considering the voltage drop of the stator resistance, then the required voltage space vector $u_{s(k+1)}^{*}$ equation [16]:

$u_{s(k+1)}^{*}=\Delta \psi_{s(k+1)} / T_{s}+i_{s} R_{s}$

then

$U_{s}^{*}=u_{s(k+1)}^{*}$

\subsection{Torque Angle Difference Closed-Loop Control (Method-First)}

To improve the performance of BASIC-DTC and not to lose the advantages of structure simple of the BASIC-DTC system, the method of torque angle difference closed-loop control ignores the increment $\Delta \theta_{s s(k+1)}$ of the steady-state phase angle of the stator flux, and then $\Delta \theta_{s(k+1)}$ is gotten with the method of torque angle difference closed-loop control to realize the control of torque and flux. Block diagram of DTC with closed-loop control of torque angle difference is shown in Fig. (4).

Compared with the method of BASIC-DTC, the system structure of the method of torque angle difference closedloop control is further simplified due to omitting the rotation inverse transformation and the hysteresis comparator of torque and flux. 


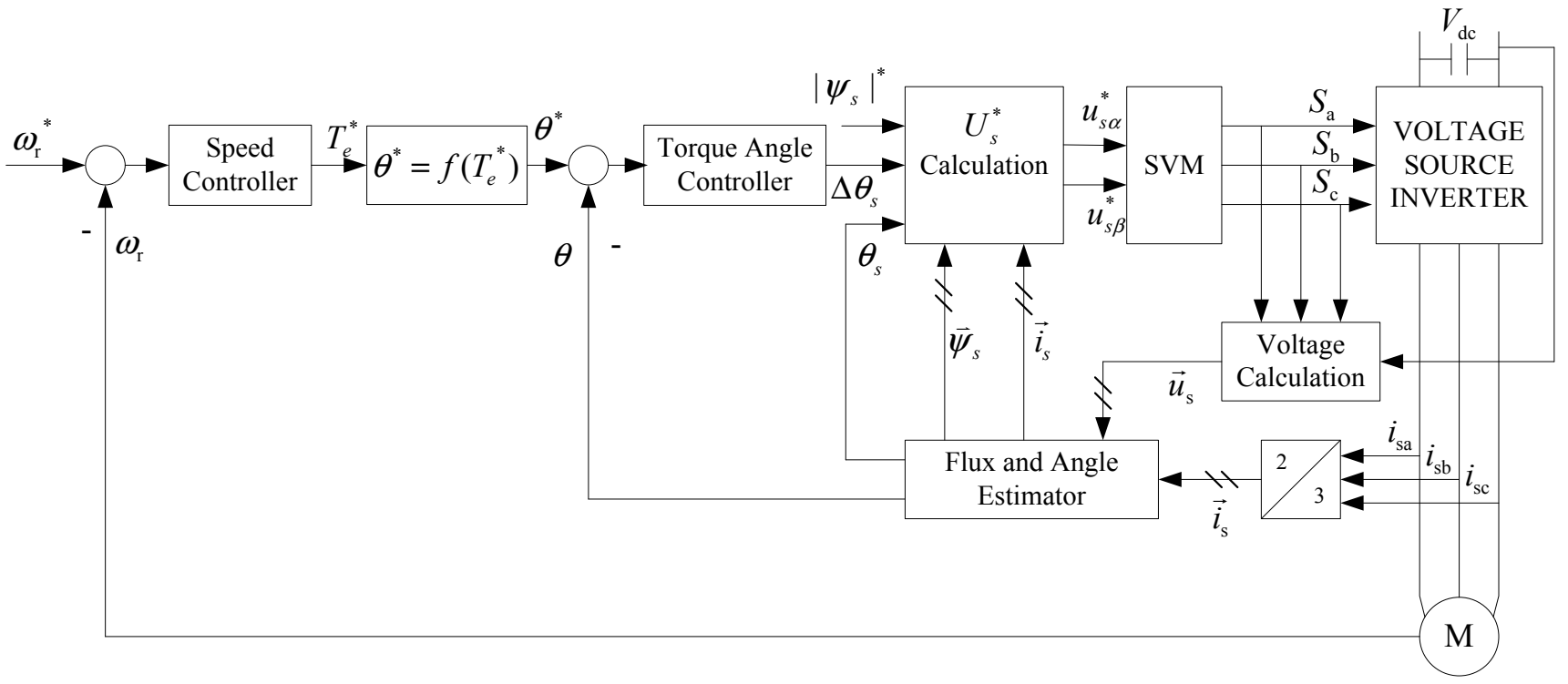

Fig. (5). Block diagram of DTC with closed-loop control of torque angle controller.

\subsection{Torque Angle PI Controller Closed-Loop Control (Method-Second)}

The method of torque angle difference closed-loop control has little effect on the torque in the system's steady-state process, although ignoring the increment $\Delta \theta_{s s(k+1)}$ of the steady-state phase angle of the stator flux. But there is a large impact on the torque in the system's dynamic process. The torque cannot maintain a constant maximum in the system's dynamic process due to ignoring $\Delta \theta_{s s(k+1)}$, thereby reducing the dynamic response of the system.

In order to maintain the inherent advantages of the BASIC-DTC's fast dynamic response, the increment $\Delta \theta_{s s(k+1)}$ of the steady-state phase angle of the stator flux is gotten to control torque and flux using the method of torque angle PI controller closed-loop control. Block diagram of DTC with the method of torque angle PI controller closedloop control is shown in Fig. (5). The torque angle controller shown in Fig. (5) is the PI controller.

The method of torque angle PI controller closed-loop control makes the torque maintain at the maximum constant in a dynamic process, and then to maintain a rapid system dynamic response. However, the advantages of the system simple structure is lost because of the usage of the torque angle PI controller.

\subsection{Torque Angle Compensation Closed-Loop Control (Method -Third)}

In order to overcome the shortcoming of the method of torque angle difference closed-loop control and torque angle PI controller closed-loop control, $\Delta \theta_{s(k+1)}$ is gotten with the method of torque angle compensation closed-loop control to realize the control of torque and flux.
The method of torque angle compensation closed-loop control not only allows the torque to maintain a constant maximum in the dynamic process, and then to get a rapid dynamic response, but also can reduce the usage of PI controller, and then has a advantages of simple structure of the BASIC-DTC system. Block diagram of DTC with the method of torque angle compensation closed-loop control is shown in Fig. (6).

\section{CALCULATION OF GIVEN TORQUE ANGLE AND FEEDBACK TORQUE ANGLE}

Another form of electromagnetic torque equation by formula (3) is:

$T_{e}=\frac{3}{2} P_{n} \cdot \frac{L_{m}}{\Delta} \cdot\left|\psi_{s}\right| \cdot\left|\psi_{r}\right| \sin \theta$

Where $\theta$ is the angle between the stator flux vector and the rotor flux vector, i.e., the torque angle.

The relationship between the torque $T_{e}$ and the torque angle $\theta$ is non-linear from formula (14). But $T_{e}$ and $\sin \theta$ is directly a proportional relationship when the amplitude of the stator flux, the rotor flux and torque is known. The scope of the torque angle is far less than $\pi / 2$ under normal circumstances. The angle range of the Induction motor torque is generally between $[-0.2,+0.2]$. The relationship between the torque angle $\theta$ and $\sin \theta$ is shown in Fig. (7).

From Fig. (7), the relationship between $\theta$ and $\sin \theta$ is approximately linear in the case of the small torque angle, and so the relationship between $\theta$ and $T_{e}$ is approximately linear. 


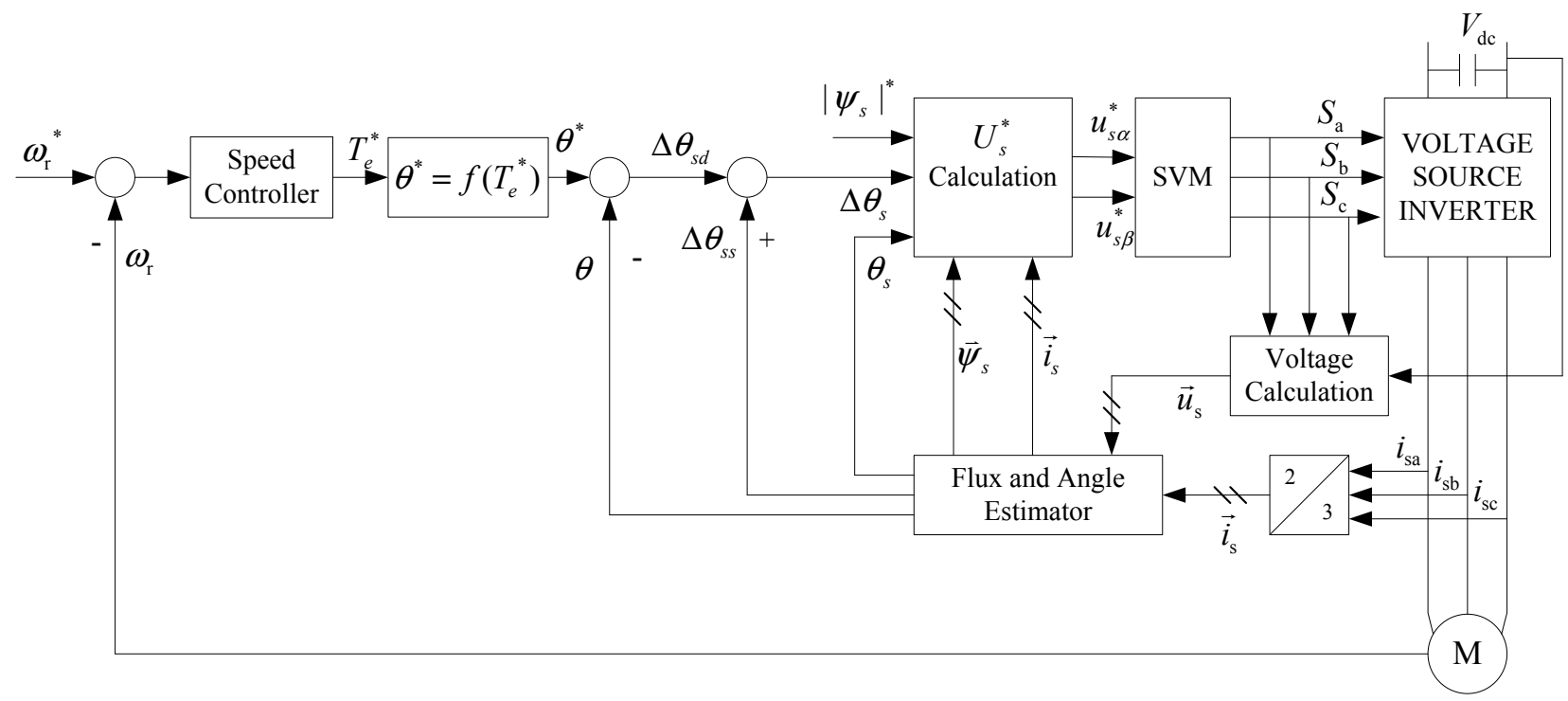

Fig. (6). Block diagram of DTC with closed-loop control of torque angle compensation.

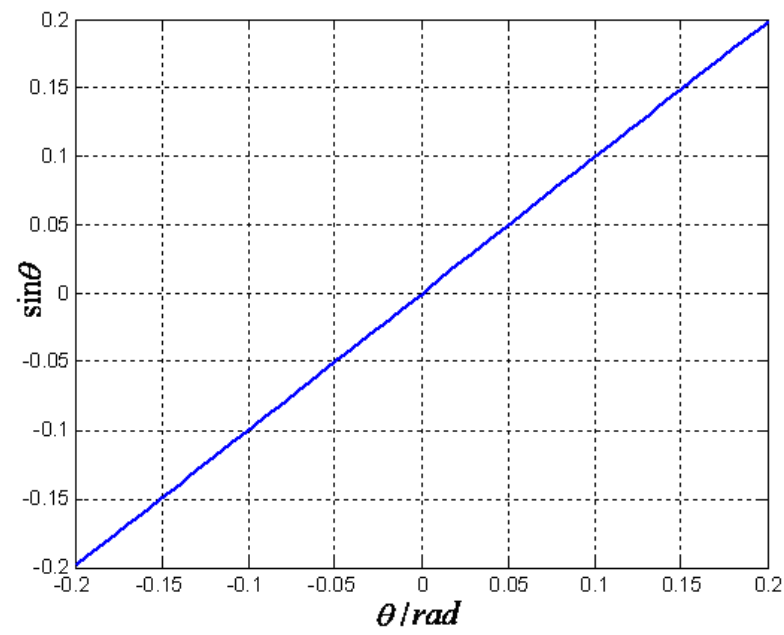

Fig. (7). Relationship between $\theta$ and $\sin \theta$.

In the condition of ignoring electromagnetic inertia of the stator and rotor, knowing the stator and rotor flux amplitude and torque, $\theta$ can be approximated by:

$\theta \approx \sin \theta=T_{e} / C_{m}$

Where $C_{m}=\left(1.5 \cdot P_{n} \cdot \frac{L_{m}}{\Delta} \cdot\left|\psi_{s}\right| \cdot\left|\psi_{r}\right|\right)$ is constant.

As can be seen from formula (15), as long as the torque $T_{e}$ is known, $\theta$ will be obtained using the torque coefficient $C_{m}$. Arcsine calculation is omitted, so that the calculation becomes simple.

The given torque angle $\theta^{*}$ can be calculated directly by equation (15): $\theta^{*} \approx \sin \theta^{*}=T_{e}^{*} / C_{m}$

Where $C_{m}=\left(1.5 \cdot P_{n} \cdot \frac{L_{m}}{\delta} \cdot\left|\vec{\psi}_{s}^{*}\right| \cdot\left|\vec{\psi}_{r}^{*}\right|\right)$ is constant.

The feedback torque angle $\theta$ can be very simply obtained based on taking full advantage of the flux observer. By the two components of the stator and rotor flux, the following equations are obtained:

$\cos \theta_{s}=\psi_{s a} /\left|\psi_{s}\right|, \quad \sin \theta_{s}=\psi_{s \beta} /\left|\psi_{s}\right|$,

$\cos \theta_{r}=\psi_{r a} /\left|\psi_{r}\right|, \quad \sin \theta_{r}=\psi_{r \beta} /\left|\psi_{r}\right|$.

Therefore

$\theta \approx \sin \theta=\sin \left(\theta_{s}-\theta_{r}\right)$

$\theta \approx \sin \theta_{s} \cdot \cos \theta_{r}-\cos \theta_{s} \sin \theta_{r}$ 


\section{SIMULATION RESULTS AND ANALYSIS}

To compare the performance of the BASIC-DTC programs and the proposed control scheme in this paper, and in order to analyze their own characteristics of the three torque angle closed-loop control methods of the proposed control scheme, the simulation models of BASIC-DTC and the three torque angle closed-loop control methods of the proposed control scheme were established, and then simulation was carried out. The same motor parameters were used in both systems.

(a) stator flux amplitude of BASIC-DTC (b) stator flux amplitude of Method-First

(c) stator flux amplitude of Method-Second (d) stator flux amplitude of Method-Third

The length of simulation time is 6 seconds, and the given rotor mechanical angle speeds are respectively $160 \mathrm{rad} / \mathrm{s}$ and $60 \mathrm{rad} / \mathrm{s}$. The systems start up when Load torque is $50 \mathrm{~N} . \mathrm{m}$, and Load Torque is $200 \mathrm{~N} . \mathrm{m}$ when the time is 4 seconds.

The simulation results were shown in Figs. (8-11) when the given rotor mechanical angle speeds are respectively $60 \mathrm{rad} / \mathrm{s}$.

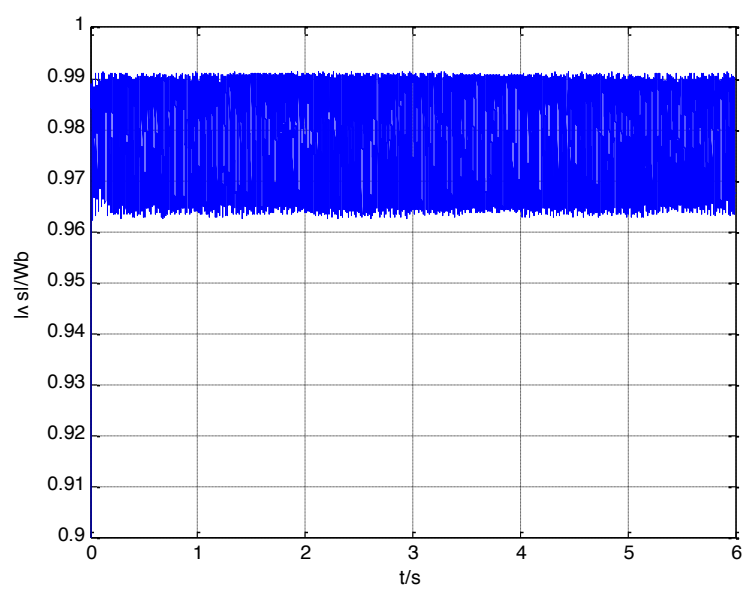

(a) Stator flux amplitude of BASIC-DTC

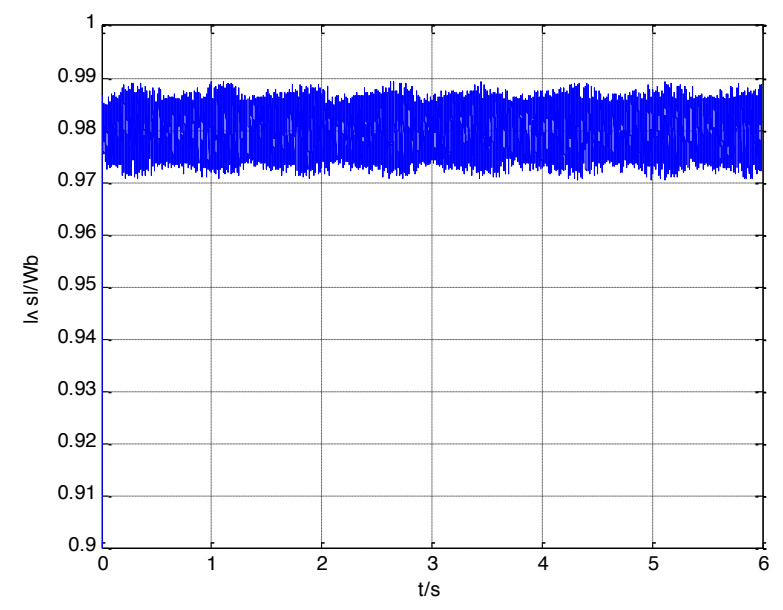

(b) Stator flux amplitude of Method-First

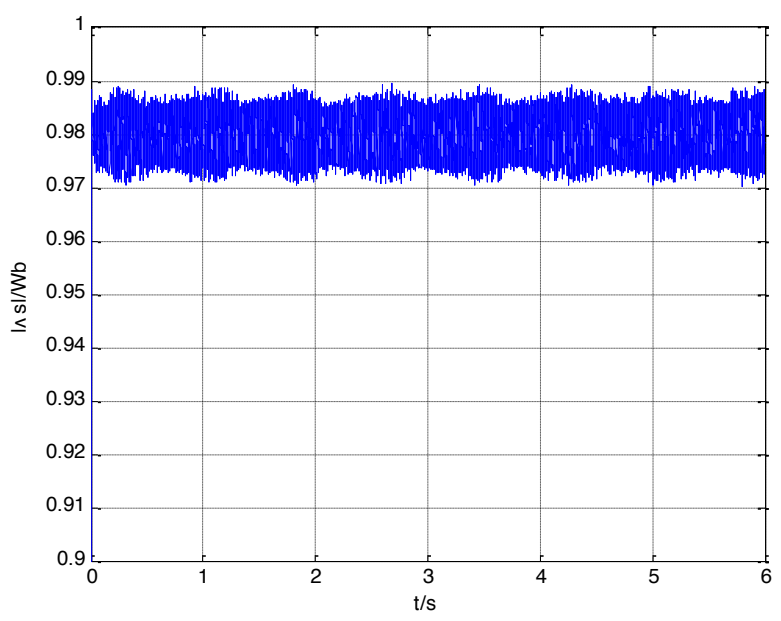

(c) Stator flux amplitude of Method-Second

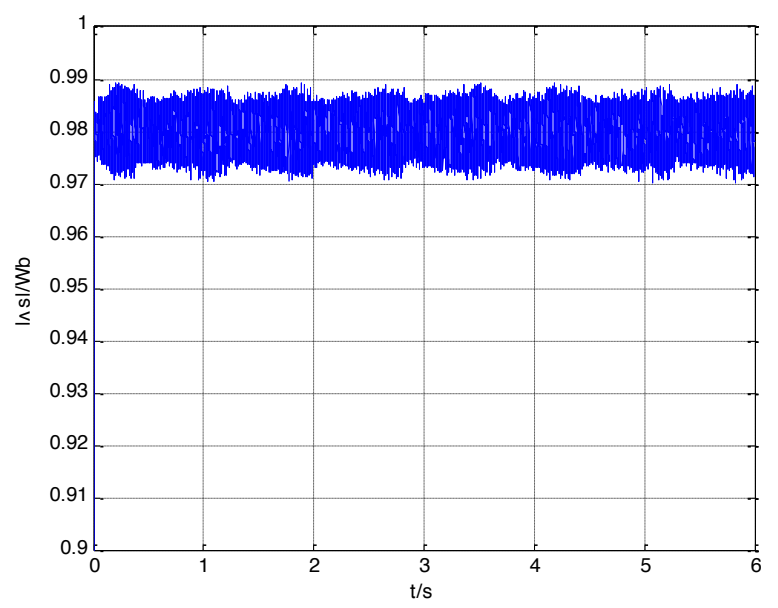

(d) Stator flux amplitude of Method-Third

Fig. (8). Waveform of stator flux amplitude when the rotor angular speed is 60rad per second.

As can be seen from Fig. (8): compared with BASICDTC, the three torque angle closed-loop control methods of the proposed control scheme make the flux ripple significantly reduced, especially at low speeds. The flux ripple has no significant difference when three torque angle closedloop control methods are compared with each other. And it was indicated that the effect on reducing flux ripple of the three torque angle closed-loop control methods is similar.

As can be seen from Fig. (9): compared with BASICDTC, the three torque angle closed-loop control methods of the proposed control scheme make the torque ripple significantly reduced, especially at low speeds. The torque ripple has no significant difference when three torque angle closedloop control methods are compared with each other. And it was indicated that the effect on reducing the torque ripple of the three torque angle closed-loop control methods is similar.

As can be seen from Fig. (10): compared with BASICDTC, the three torque angle closed-loop control methods of the proposed control scheme make the current waveform distortion significantly reduced, especially at low speeds. 
The current waveform distortion has no significant difference when three torque angle closed-loop control methods are compared with each other. And it was indicated that the effect on reducing the current waveform distortion of the three torque angle closed-loop control methods is similar.

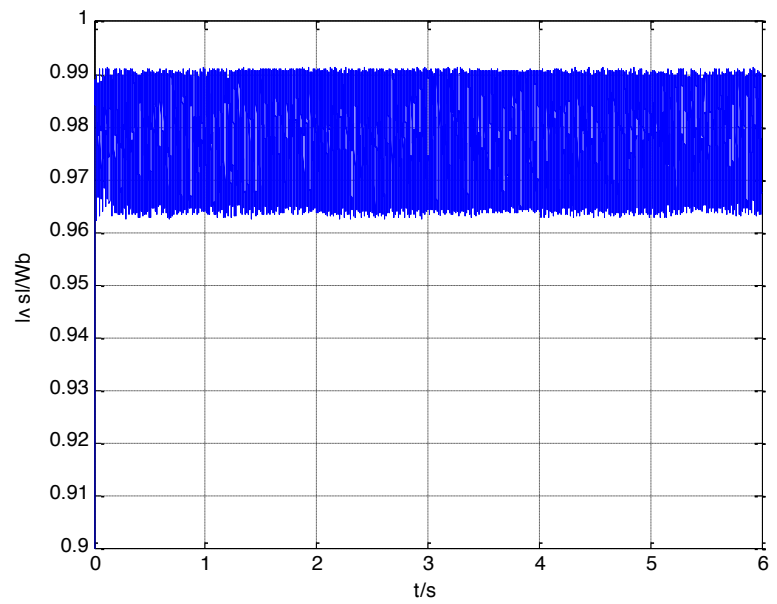

(a) Torque of BASIC-DTC

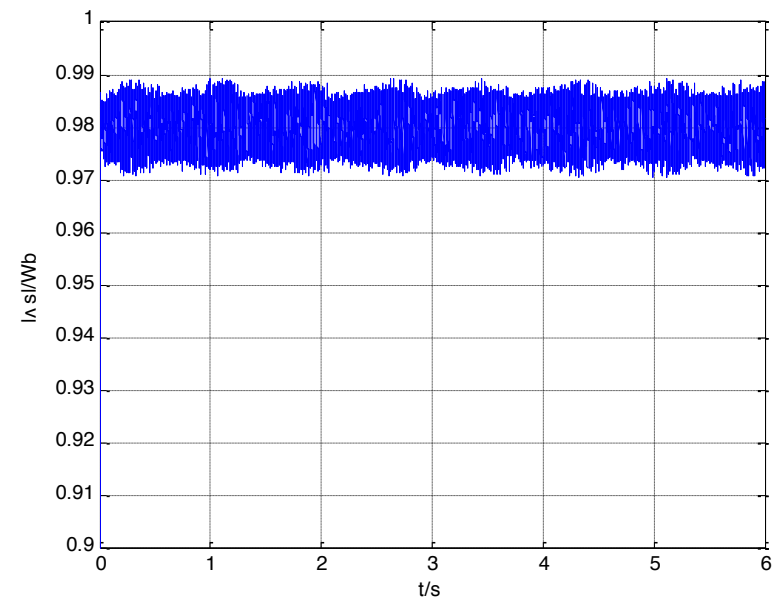

(b) Torque of Method-First

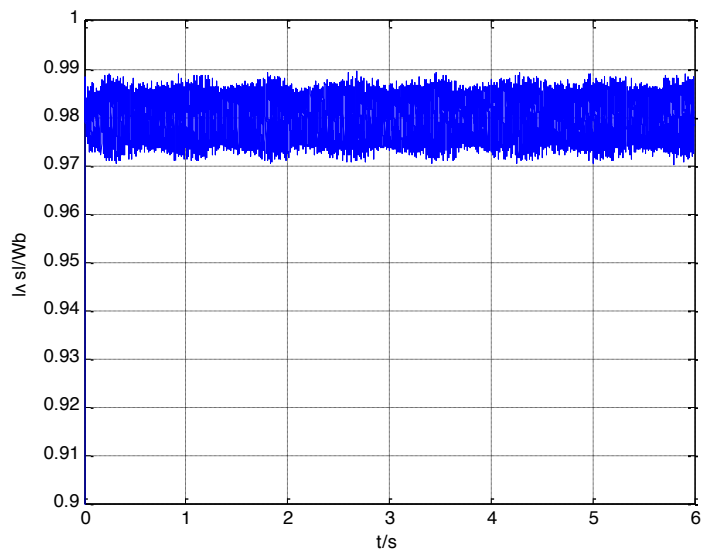

(c) Torque of Method-Second

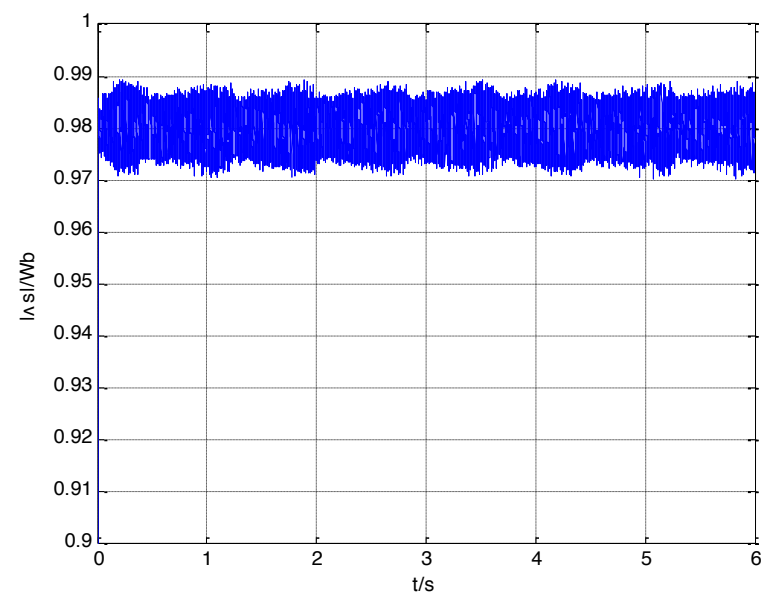

(d) Torque of Method-Third

Fig. (9). Waveform of torque when the rotor angular speed is 60rad per second.

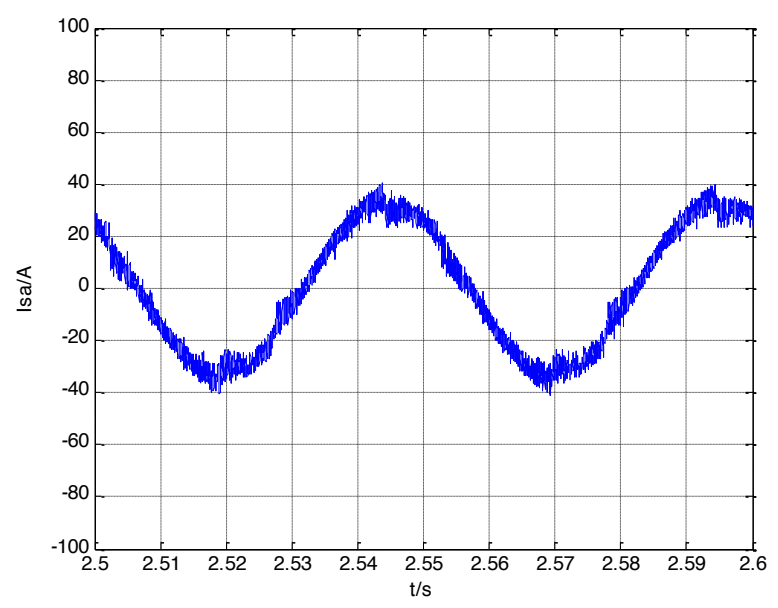

(a) Stator current of BASIC-DTC

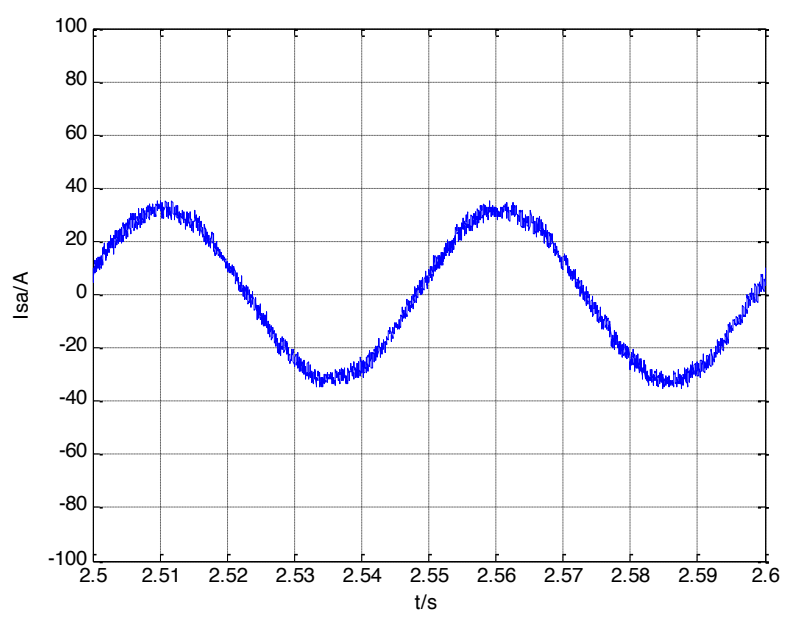

(b) Stator current of Method-First

Fig. (10). Contd... 


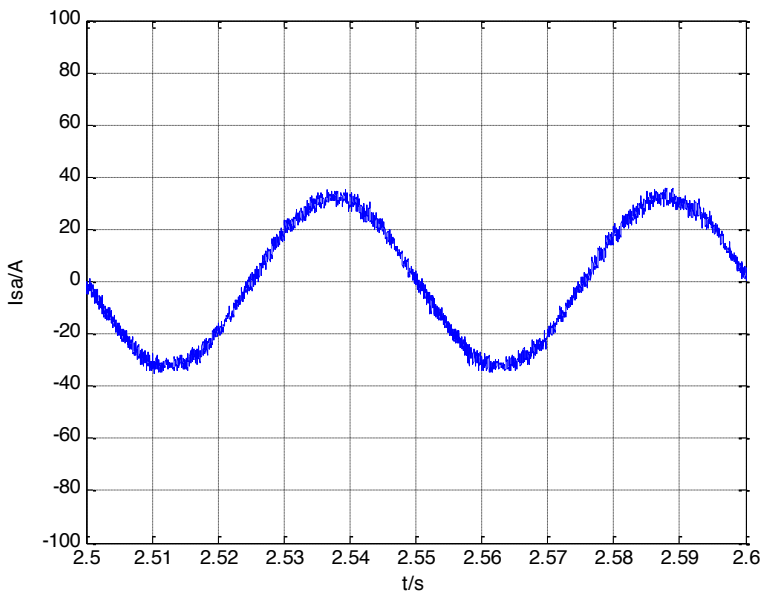

(c) Stator current of Method-Second

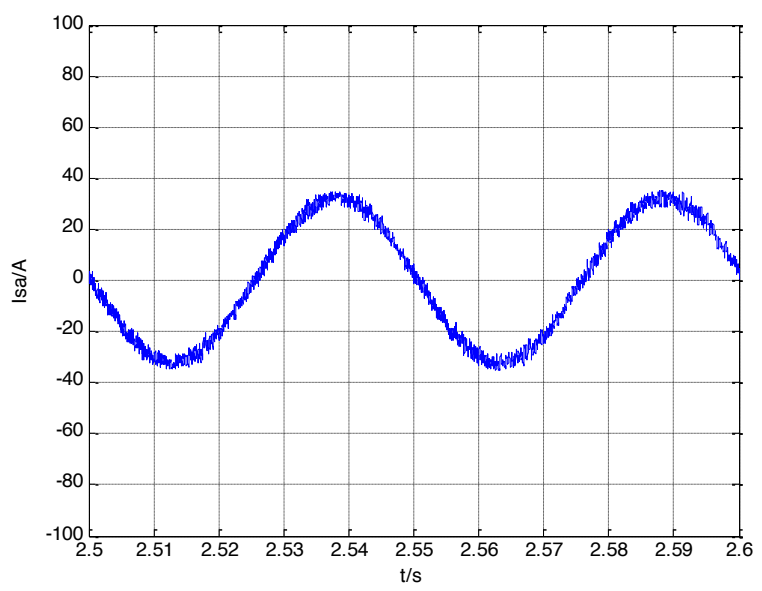

(d) Stator current of Method-Third

Fig. (10). Waveform of stator current when the rotor angular speed is $60 \mathrm{rad}$ per second.

As can be seen from Fig. (11): torque angle PI controller closed-loop control and torque angle compensation closedloop control can be obtained at the same speed dynamic response as BASIC-DTC. The dynamic speed response of torque angle difference closed-loop control is slower than BASIC-DTC, because its torque in the dynamic process cannot maintain a constant maximum.

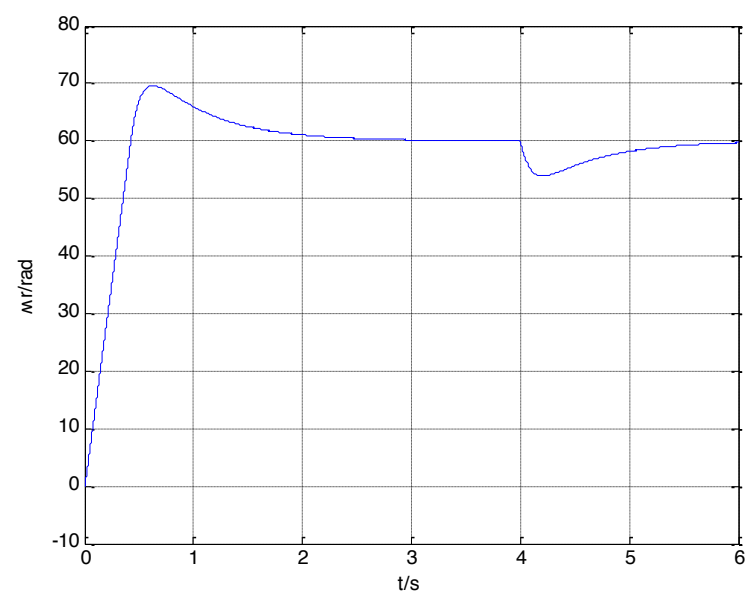

(a) Speed of BASIC-DTC

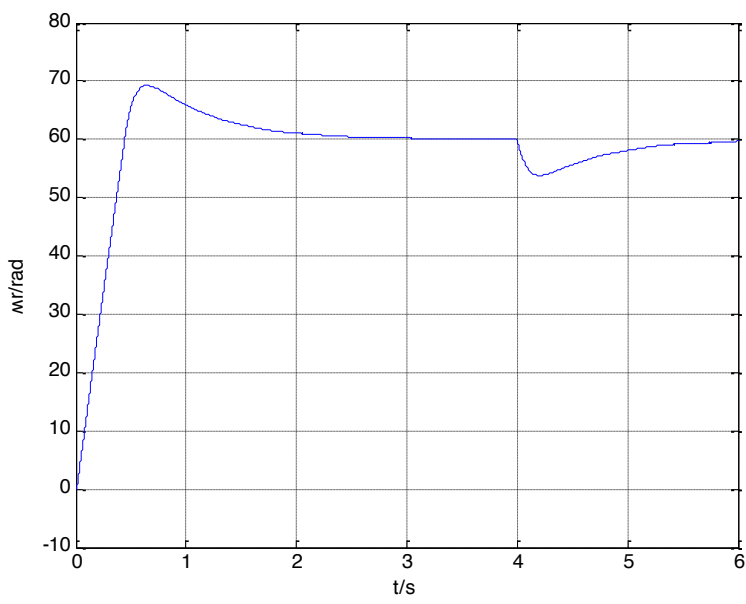

(b) Speed of Method-First

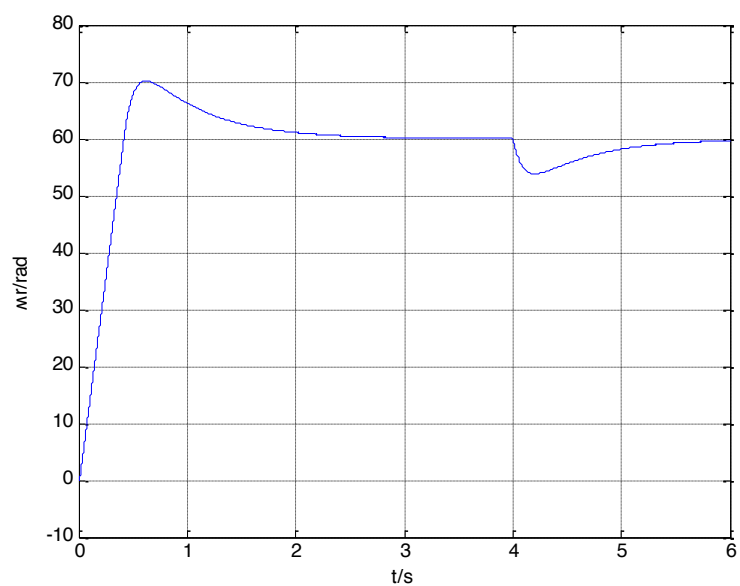

(c) Speed of Method-Second

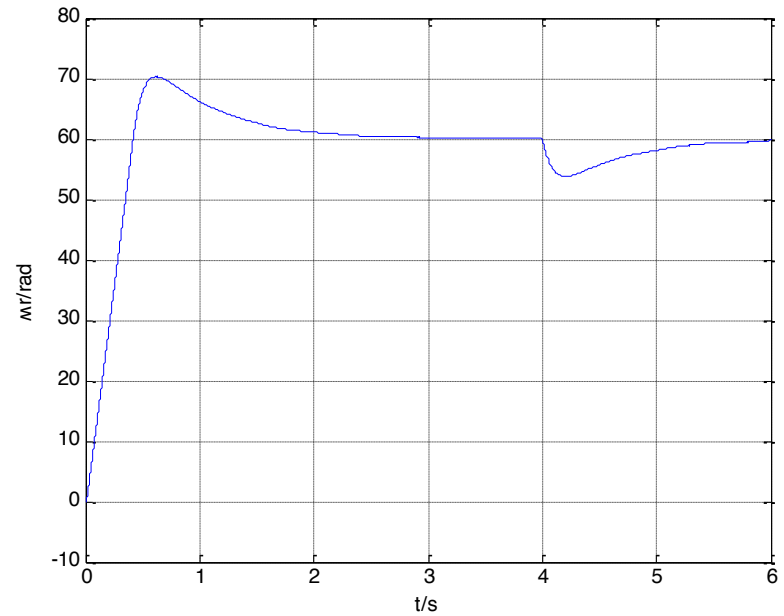

(d) Speed of Method-Third

Fig. (11). Speed waveform when the rotor angular speed is $60 \mathrm{rad}$ per second.

\section{CONCLUSION}

The DTC Scheme for induction motor based on torque angle closed-loop control was presented in this paper. The control of induction motor was realized using three methods 
of torque angle closed-loop control. The principle of three methods of torque angle closed-loop control for the proposed scheme was analyzed. Three methods of torque angle closedloop control improved the performance of the system in three areas such as flux ripple, torque ripple and current waveform distortion. Three methods of torque angle closedloop control have their own characteristics:

Torque angle difference closed-loop control has a more simple system configuration, but its dynamic response was affected.

Torque angle PI controller closed-loop control maintains the inherent advantage of the fast system dynamic response, but the usage of PI regulator increases the difficulty of the system parameter design.

Torque angle compensation closed-loop control not only overcomes the shortcomings of the other two methods, while maintaining the fast dynamic response, but also it has a simple system architecture.

\section{CONFLICT OF INTEREST}

The authors confirm that this article content has no conflict of interest.

\section{ACKNOWLEDGEMENTS}

Declared none.

\section{REFERENCES}

[1] B.K. Bose, Modern Power Electronics and AC drives. PrenticeHall, Upper Saddle River, 2002.

[2] F. Blaschke, "The principle of fields-orientation as applied to the Transvector closed-loop control system for rotating-field machines", Siemens Review, vol. 34, pp. 217-220, 1972.

[3] M. Depenbrock, "Direct self-control (DSC) of inverter-fed induction machine", IEEE Transactions on Power Electronics, vol. 3, pp. 420-429, 1988.

[4] Y. Xue, X. Xu, T.G. Habetler, and D.M. Divan, "A low cost stator flux oriented voltage source variable speed drive", In: Conference
Record of the 1990 IEEE Industry Applications Society Annual Meeting, vol. 1, pp. 410-415, 1990.

[5] H.M. Kojabadi, and L. Chang, "Comparative study of pole placement method in adaptive flux observers", Control Engineering Practice, vol. 13, pp. 49-757, 2005.

[6] I. Takahashi, and T. Noguchi, "A new quick-response and high efficiency control strategy of an induction machine", IEEE Transactions on Industry Applications, vol. 22, pp. 820-827,1986.

[7] M. H. Toodeshki, S. Hosseinnia, and J. Askari, "Adaptive robust control of uncertain systems with state and input delay", International Journal of Control, Automation, and Systems, vol. 8, pp.1212-1220, 2010

[8] A. Sivasubramanian, and B. Jayanand, "Application of neural network structure in voltage vector selection of direct torque control induction motor," International Journal of Mechanics and Thermodynamics, vol. 1, pp. 71-80, 2010.

[9] V. Kumar, "Modified direct torque control of three-phase induction motor drives with low ripple in flux and torque", Leonardo Journal of Science, vol. 18, pp. 27-44, 2011.

[10] S. Belkacem, F. Naceri, and R. Abdessemed, "Improvement in DTC-SVM of AC drives using a new robust adaptive control algorithm", International Journal of Control, Automation, and Systems, vol. 9, pp. 267-275, 2011.

[11] Y. Zhang, J. Zhu, Z. Zhao, W. Xu, and D. G. Dorrell, "An improved direct torque control for three-level inverter-fed induction motor sensorless drive," IEEE Transactions on Power Electronics, vol. 27, pp. 1502-1513, 2012.

[12] R. Rajendran, and Dr. N. devarajan, "A comparative performance analysis of direct torque control schemes for induction motor drives", International Journal of Power Electronics and Drive System, vol. 2, pp. 177-191, 2012.

[13] C.H. Krishna, J. Amarnath, and S. Kamakshiah, "A simplified SVPWM algorithm for multi-level inverter fed DTC of induction motor drive", International Journal of Engineering and Innovative Technology, vol. 1, pp. 61-67, 2012.

[14] F.R. Hassan, "Modified direct torque control using algorithm control of stator flux estimation and space vector modulation based on fuzzy logic control for achieving high performance from induction motors", IEEE Transactions on Power Electronics, vol. 13, pp. 369-380, 2013.

[15] F.R. Hassan, and N.M.L. Tan, "DTC-SVM based on pi torque and pi flux controllers to achieve high performance of induction motor", Research Journal of Applied Sciences, vol. 7, pp. 875-891, 2014

[16] F.B. Salemand and N. Derbel, "Performance analysis of DTC-SVM sliding mode controllers-based parameters estimator of electric motor speed drive", Mathematical Problems in Engineering, vol. 2014, pp. 1-11, 2014 